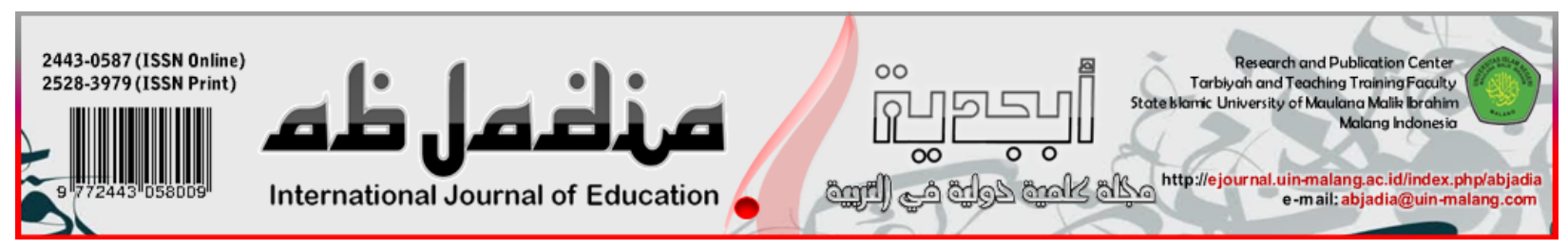

\title{
ANALYSIS OF LINGUISTIC ELEMENTS IN THE TEXTBOOK OF $A L-$ ARABIYYAH LI AN-NASYI'IN AND ITS CONTRIBUTION TO THE ARABIC LANGUAGE DEVELOPMENT PROGRAM
}

\section{تحليل العناصر اللغوية في كتاب العربية للناشئين ومساهمتها في برنامج تطوير اللغة العربية}

\author{
Nur Faiz Kholidiyah \\ Universitas Negeri Malang, Indonesia
}

Article History:

Received : 2020-12-05

Revised : 2021-04-27

Accepted : 2021-05-10

Published : 2021-06-30

\section{Keywords:}

Linguistic, Textbook, Al-Arbiyah Li

An-Nasyi'in

*Correspondence Address:

noorafaizz@gmail.com

\begin{abstract}
This study aims to determine the suitability of the contents in the Textbook of Al-Arabiyyah Li An-Nasyi'in with language elements and their contribution to the Arabic Language Development Program of the State Islamic University of Maulana Malik Ibrahim Malang. This research uses qualitative and quantitative approaches. Based on the data analysis that has been carried out, the results of this study indicate that 1) The percentage of the suitability of the Fonology, Morfology, Vocabulary, Listening, Speaking, Reading and Kitabah in the Textbook of Al-Arabiyyah Li An-Nasyi' in respectively is $25 \%, 85 \%, 75 \%, 30 \%, 55 \%, 35 \%$, and $60 \%$; 2 ) the percentage of the contribution level of the language element is $65.6 \%$ with the criteria of sufficient contribution.
\end{abstract}

يتكوّن تعليم اللغة العربية من أنواع عناصر متربطة ليبلغ هدف معين، وهو عملية تفاعل بين

شخصين أو أكثر وفيه نظام (Nazarmanto \& Istiqomah, 2019). ومن عناصر التعليم خاصة في اللغة (Zulhannan, العربية فيما أهداف التعليمية، طرائقها، مداخلها، أساليبها، وسائلها وكتب الدراسية (2015، إنّ كل عنصر من هذه العناصر له دور مهم في التعلم. يحتل الكتاب المدرسي موقعا مهما أسـاسيا في عملية التعليم. يعتبر الكتاب المدرسي مساعدة ووسائل في تشكيل عقلية الطلاب وتحقيق المفاهيم أي مساعدة الطلاب وتكوين قدراته وتنمية مواهباء وزيادة معارفه وحسن السلوك وإكسابا المعارف والمهارات المختلفة وتنمية الاتجاهات السلوكية البناءة. وقال Alan Cunningsworth من مواصفات الكتاب المدرسي الجيد يحتوي على حاجة الطلاب بتعليم اللغة اتصاليا، مساعدة الدارسين في تنمية مهارة الأربع ودراسـة القواعد النحوية البنيوية (Prima \& Habib, 2019). 
يؤثر الكتاب الدراسي تأثيرا كثيرا فينبغي على إعداد الكتاب الدراسي بعناية وبدقة. وفقا ل عبد الحميد يشمل الكتاب الدراسي الجيد على المكوّن الرئيسي المكوّن التكميلي والمكوّن التقويمي. يحتوي المكوّن الرئيسي على موضوعات سيدرسها الطلاب، ويحتوي المكوّن التكميلي على إثراء للطلاب، ويحتوي المكوّن التقويسي على اختبارات للطلاب (Hamid, Baharuddin, \& Mustofa, 2008). والتالي قال عبد الله، تتضيمن الكتاب المدرسي على أربعة أسس ألا وهي الأسس الثقافية والاجتماعية، الأسس السيكولوجية، الأسس التربوية والأسس اللغوية (قدري \& فضل, 2019).

تتعلق الأسس الثقافية والاجتماعية باللغة، فاللغة وعاء الثقافة والثقافة يعتبر باللغة. ومن يتعلم لغة أجنبية معينة لن يكون قادرًا على فهمها جيدًا دون فهم ثقافة المجتمع. والأسس السيكولوجياة تتعلق بالقدرة والاستعداد لتعلم لدى الطلاب، وعند تقديم المواد التعليمي لابدّ على المعلم الانتباه إلى سيكولوجية الطلاب وأن يكون متوافقًا مع القدرات المعرفية للطلاب حتى يتمكن من زيادة دافع الطلاب للتعلم. والتالي الأسس التربوية تتعلق بالنظريات التربوية في استخدام واستفادة الكتاب الدراسي حتى لا يخرج الكتاب الدراسي عن النظرية التربوية الراسخة. والأخير الأسس اللغوية يشمل من أصهوات ومفردات وتراكب ومهارة اللغة الأربع (Hamid et al., 2008).

لقد انتشرت كتاب العربية للناشئين "2" يستخدمها بعض المدارس والمعاهد لتدريس اللغة العربية، المثل في برنامج تطوير اللغة العربية جامعة الإسلامية الحكومية مولانا مالك إبراهيم مالانج. وذُكِر عبد العزيز أنهّا مطابقا لتعليم اللغة العربية لغير الناطقين بها عموما، إلاّ أنّه فات منه بعض المعايير التي ذات أهمية وهي اختبار أو تقويم ومعجم لمعاني مفردات الكتاب (Siddiq, 2019). وذكرت هالشَة أنّا يجعل الطلاب سهولة في فهم، حماسيا، جذابة ومسرورا عند التعليم ولكنّ بالأسف الشـيد أنّ الصور في هذا الكتاب الصور القديمة وليس من الصور الحديثة (العله, 2018). ذكر نور حليم أنها سهولة في الفهم ولكن تحتاج إلى إضيافة وسائط تكميلية، مثل الأفلام (Halim, 2020). بناء على ذلك، فلا بد للكتاب المدرسي معايير حتي تكون كتابا جيدا ومناسبا. ذلك أن الكتاب الدراسي في حالتنا هذه ليس مجرد وسيلة معينة على التدريس فقط، وإنّما هو صلب التدريس وأسـاسها لأنّا هو الذي يحدّد للطلاب ما يدرساء من الموضيوعات وهو الذي يبقي عملية التعليم حسنا (Mukmin, 2018). ولأنّ إعداد الكتاب الدراسي الذي لا تستند إليه جوانب من الكتب الجيدة تكون خاسرة للطلاب (Abrar, 2017). واستنادا على البحوث العلمية المذكورة، تم إجراء هذا البحث على كتاب العربية للناشئين "2" لمعرفة مدى ملاءمة محتوى كتاب العربية للناشئين "2" مع عناصر اللغة ولمعرفة مساهمته. 


\section{إن}

\section{عناصر اللغة}

يتطلب تعلم اللغة العربية لغبر الناطقين بها إتقان ثلاث عناصر اللغة هي المفردات، الأصوات والتراكيب والتالي أربع مهارات هي الاستماع، الكلام، القراءة والكتابة (Ismail, 2019). تعدّ المفردات اللغوية ذات أهمية كبري في مجال تعليم اللغات الأجنبية فالمفردات اللغوية هي مفتاح تعليم اللغات الأجنبية. وينبغي للمعلمين أن يختر المفردات من الأسس التربوية التواتروالتوزع والمتاحة والألفة والشمول (السلام, 2020). (الس).

الأصوات هي آلة اللفظ، ولن تكون حركات اللسان لفظًا ولا كلامًا موزونًا ولا منثورًا إلاّ بظهور الصيوت. فالعلم الأصيوات هو العلم الذي يدرس الصوت الإنساني من وجهة الدرس اللغوي. استفاد اللغويون من علم الأصروات في تطوير علم الصرف والنحو، وذلك باعتماد الخصائص الصيوتية في تقعيد القواعد على أسـاس منطقية سليمة (Hasan, 2018).

مهارة الاستماع هي ليس بمجرد استقبال الصوت المسموع، وإدراك وفهم واستيعاب ما يحمل من ألفاظ وجمل وتعبيرات فحسب ولكن يلزماه توافق تام بين كل من المتكلم والمستمع وفياه بذل جهد ضمني حتى يكون قادرا على استخلاص المعلومات وتحليلها ونقدها حتى يتحقق التواصل بين المتكلم والمستمع أي أنّ عملية الاستماع تتكون من أربعة الأركان، فيما يلي : فهم المعنى الإجمالي، تفسير الكلام والتفاعل معه، تقويم الكلام ونقده وربط المضمون المقبول بالخبرات (لوبيس, 2019). مهارة القراءة هي القدرة على التفاعل مع ما يقرأ بشكل صحيح وبسرعاة مناسبة مع فهم المقروء وتقاس إجرائيا في الاختبار وفيه عمليات عقلية علي التفكير والتقويم والحكم والتحليل والتعليل وحلّ المشكلات (العليمات \& داود, 2019). ويمكن نستفيد المعارف أي الوصول إلى المعلومات واستخراج النتائج من القراءة لأنهّا مفتاح العلوم (Halimah, 2019). مهارة الكلام هي القدرة على امتلاك الكلمة الدقيقة الواضحة ذات أثر في حياة الإنساني فيها تعبير عن نفساه وقضاء لحاجتاه وتدعيم لمكانته في التفاعل الاجتماعيّ والتمكن من الصيخ النحوية ونظام ترتيب

الكلمات التي تساعده على التعبير عما يريد أن يقول في موافق الحديث (Khoirurrijal \& Erlina, 2019). مهارة الكتابة هي وسيلة من وسائل الاتصال الإنساني يتم على طريقتها التعريف على أفكار الغير سواء كان قدرة تعويد الطلاب على حسن التعبير في نفوسهم وما يقع حواسهم بالعبارة الصحيحة Umar) 
\&ahruddin, 2018) كتابة الحروف الذي يتم التركيز فيها على الرسم لرموز اللغة وأما الفكرية العقلية تتمثل في جانبي التعبير عن الأفكار في شكل مسلسل طبقا لنظام تركيب اللغة (Hafidz, 2018).

$$
\text { الكتاب الدراسي }
$$

الكتاب الدراسي هو الكتاب الأسـاسي للطالب وما يصبحها من مواد تعليمية مساعدة، والتي تؤلف من قبل المتخصصين في التربية واللغة، وتقدم للدارسين لتحقيق أهداف معينة وهي معرفية أو وجدانية أو نفس حركية في مقرر معين لمرحلة وزمن محدد (Siddiq) 2019). يشمل الكتاب الدراسي على ثلاثة مكونات : أولها الاساسية وهي المكون الأساسي وثنيها المواد المساعدة منها المعجم وكراسة التدرببات التحريرية وكراسـة التدريبات الصوتية وكتب قراءة مصاحبة ومتدرجة مع الكتاب الأساسي وكراسـة اختبارات ومرشد المعلم، وثالثها الوسائل السمعية والبصرية المعينة (Hamid et al., 2008). أنّ الكتاب الدراسي له أهميات كبرى في إجراء التعليم والتعلم وليكون وسيلة أسـاسية ومسـاعدة للمعلم في تقديم المواد الدراسية للطلاب. أنّه الوعاء الذي يحمل المعلومات والاتجاهات المراد غرسها في الطلاب بل للمعلمين وغيرهم فهو يمدهم بالخبرات والحقائق ومصيدر ثقافي لهم. وقال هدايات، مع أهمية فلا بد للكتاب الدراسي : (1) أن يسيطر عليها الطلاب للحصول على الأهداف الدراسية المنشودة، (2) يستخدم شكل منظم، (3) يمكن للطلاب أن يطالع ويراجع المادة الدراسية بنفسـه دون توجيهات المعلم (دري \& فضل, 2019).

إنّ الكتاب الدراسي الجيد لمتعلمي اللغة العربية الناطقين بغيرها لابد أن يشتمل على : 1. مقدمة الكتاب : تتضمن أهدافه الأساسية وكيفية عرض محتواه وإشارة إلى مضمون وحداته

2. الأهداف التعليمية : أن تراعي حاجات الطلاب وثقافاتهم ومستواهم اللغوي، وأن تتسم بالتنوع (معرفية - مهارة - وجدانية)، والشمول (تذكر - فهم - تطبيق - تحليل - تركيب - تقويم)، وقابلية القياس.

3. المحتوي : أن يركز على ثقافة اللغة الهدف وأن يرتبط بأهداف الكتاب وبخبرات الطلاب متماسگًا ومتسلسلاً. 
4. الأنشطة : الأنشطة بنائية ومتنوعة وقابلة للتطبيق، وتصف النشاط بأسلوب مبسط ومفهوم، وأن يتبع تغدية راجعة ترشد إلى عملية التطوير.

5. الصوار والرسومات : اختيار صور ورسوماته بشكل دقيق لأهميتها القصوى في مجال تعليم اللغات.

6. أسـاليب التقويم : التقويم المكثف لتثبيت ما تعلمه الطلاب من حصيلة لغوية، وأن يكون متنوعا وشاملا ومستمرا ومتكاملا بين المهارات اللغوية المختلفة ومتسقا مع أهداف الكتاب. 7. الإخراج الفني : مظهره جميل وتجليده متين وخطه واضح ورسوماته معبرة وعنوانه جذاب وترتيبه مناسب وحجماه ملائم ومسافتـه متناسقة (الفوزان, 2019). والتالي قالا أمير الدين وأشرف الأخيار، يجب من مواصفات الكتاب المقرر إلى مراعة علاقة التعليم بالأهداف المنشـودة، قضيايا لغوية، حاجة الدارسين والعلاقة بين اللغة والتعليم والدارس (Amiruddin, Muhammad; Akhyar, 2019). قال عبد الله، تتضيمن الكتاب المدرسي على أربعة أسس ألا وهي الأسس الثقافية والاجتماعية، الأسس السيكولوجياة، الأسس التربوية والأسس اللغوية 1. الأسس الثقافية والاجتماعية، فاللغة وعاء الثقافة والثقافة يعتبر باللغة. ومن يتعلم لغة أجنبية معينة لن يكون قادرًا على فهمها جيدًا دون فهم ثقافة المجتمع. لذا ينبغي للكتاب الدراسي لله طابع اجتماعي وثقافي إسلامي. وذلك من خلال مراعاة الآتي : - - أن يكون محتواه عربيا إسلاميا وأن يتضمن بصورة تناسب

$$
\text { - الاهتمام بالتراث العربي وخصائصها }
$$

- - التدرج في تقديم الثقافة بما تناسب مع مستوى الفكري - - مساعدة الدارسين على عملية التطبيع الاجتماعي 2. الأسس السيكولوجية، تتعلق بالقدرة والاستعداد لتعلم لدى الطلاب، وعند تقديم المواد التعليمي لابدّ على المعلم الانتباه إلى سيكولوجية الطلاب وأن يكون متوافقًا مع القدرات المعرفية للطلاب حتى يتمكن من زيادة دافع الطلاب للتعلم. والشروط النفسية التي يجب مراعاتها : - مناسبا لمستوى الطلاب فكريا، ويراعي مبدأ الفروق الفردية - م - ميساعد على تنمية اكتساب اللغة الأجنبية - - - التكامل بين الكتابي الأسـاسي ومصياحبتها - تبني المادة العلمية يشبع دوافع الطلاب ويرضي رغباتهم ويناسب ميولهم 
3. الأسس التربوياة، تتعلق بالنظريات التربوية في استخدام واستفادة الكتاب الدراسي حتى لا يخرج الكتاب الدراسي عن النظرية التربوية الراسخة.

4. الأسس اللغوية، يشمل من أصيوات ومفردات وتراكب ومهارة اللغة الأربع : مهارة الاستماع ومهارة

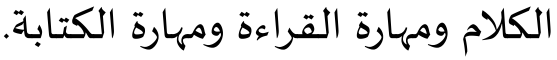

[ن] منهج

يستخدم هذا البحث على المدخل الكيفي والكمي. تم اختيار المدخل الكيفي من قبل الباحثة للحصول على معلومات مفصلة ومعمقة عن العناصر اللغوية الواردة في كتاب العربية للناشئين "2". أما بالنسبة للمدخل الكمي فقد تم اختيارها من قبل الباحثة للحصول على نتيجـة تقييم دقيقة بخصوص المساهمة في التعلم.

البيانات التي تم الحصول عليها من هذا البحث هو في شكل ثلاثة عناصر لغوية وأربع مهارات لغوية واردة في كتاب العربية للناشئين "2" ونتائج الاستبانة الطلاب في برنامج تطوير اللغة العربية جامعة الإسلامية الحكومية مولانا مالك إبراهيم مالانج. تكونت مصيادر البيانات هذا البحث من كتاب العربية للناشئين "2" ونتائج الاستبانة الطلاب في برنامج تطوير اللغة العربية جامعة الإسلامية الحكومية مولانا مالك إبراهيم مالانج.

\section{نتائج}

بناءً على تحليل البيانات الذي تم إجراؤه، كانت نتائج ملاءمة العناصر اللغوية في كتاب العربية للناشئين "2" مع أحكام العناصر اللغوية في الكتاب المدرسي على النحو التالي : أ) نسبة نتائج ملاءمة عناصر الأصرات 25\%، تدخل هذه النسبة ضمن فئة غير ملائم أي غير مناسب لأن قيمة النسبة أقل من 49.9 . ب) نسبة نتائج ملاءمة عنصر المفردات 85\%، يتم تضمين هذه النسبة المئوية في فئة مناسبة جدًا لأنّ قيمة النسبة المئوية أكثر من 80\% . ج) النسبة المئوية لنتائج ملاءمة عنصر التراكيب 75\%، يتم تضمين هذه النسبة في فئة مناسبة لأن قيمة النسبة تتراوح بين 60\% - 79.9\% . د) النسبة المئوية لنتيجة ملاءماة عناصر الاستماع 30\%، تم تضمين هذه النسبة في فئة غير ملائم لأن القيمة المئوية أقل من 49.9\% هـ) نسبة نتائج مطابقة عنصر الكلام 55\%، تدخل هذه النسبة ضمن فئة الملائمة الكافية لأن قيمة النسبة تتراوح بين 50\% - 59.9\% . و) نسبة نتيجة مطابقة عناصر القراءة 35\%، تم تضمين هذه 
النسبة في فئة غير ملائم لأن القيمة المئوية أقل من 49.9\% . ز) نسبة نتائج ملاءمة عناصر الكتابة 60\%، يتم تضيمين هذه النسبة في فئة أقل ملاءمة.

وأظهرت نتائج البيانات المتعلقة بمستوى مساهمة العناصر اللغوية الواردة في كتاب العربية للناشئين "2" في برنامج تطوير اللغة العربية جامعة الإسلامية الحكومية مولانا مالك إبراهيم مالانج أنّ النسبة المئوية لمستوى مساهمة العناصر اللغوية كانت 65.6\% مع معايير المساهمة الكافية.

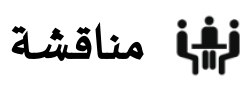

\section{مطابقة العناصر اللغوية في كتاب العربية للناشئين "2"}

أنّ للمفردات أهمية خاصة تقرض لها موقعا خاصيا في تعليم اللغات. ولا بد من إختياره يشتمل

عليها الكتب. المفردات هي عامل من عوامل المهمة في اللغة العربية لأنهّا الكلمة التي تدل على معنى. وأما أهدافه هي معرفة المعنى لفهم المقروء والمسموع، القدرة على الترجماة، استعمال الكلمة المناسبة بالتعبير الشفهي والكتابة وفقا لسياقها الصحيح (Hasanah, 2020). بناءً على نتائج البحث في الفصل السابق، تم إدراج ملاءمة عناصر المفردات في كتاب العربية للناشئين "2" في فئة مناسبة جدا، لأنّ قيمة النسبة المئوية للملاءمة هي 85\%. تتوافق عناصر المفردات في كتاب العربية للناشئين "2" بفئات مناسبة للغاية مع أحكام عناصر اللغة لأنها تلبي عدة مكونات تستخدم كمرجع لتصميم الكتب المدرسية، باستثناء مكون أهداف التعلم. لا يقدم كتاب العربية للناشئين "2" أهدافاً تعليمية تتعلق بعناصر لغة المفردات. الجدوال 1 : نتيجة تحليل عناصر اللغة (المفردات )

\begin{tabular}{|c|c|c|c|c|c|}
\hline \multicolumn{4}{|c|}{ الدرجة } & \multirow{2}{*}{ المؤشرات } & \multirow{2}{*}{ عناصر اللغة } \\
\hline \multirow[t]{2}{*}{4} & 3 & 2 & 1 & & \\
\hline & & & V & 1. أهداف التعلم & \multirow{5}{*}{ 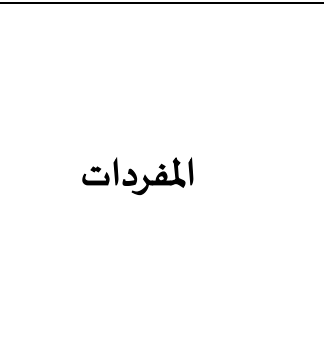 } \\
\hline v & & & & 2. المواد التعليمية & \\
\hline V & & & & 3. الأمثلة والرسوم التوضيحية & \\
\hline V & & & & 4. تدريبات وتمرينات & \\
\hline $\mathrm{V}$ & & & & 5. الواجبات الذاتي & \\
\hline \multicolumn{5}{|c|}{17} & النتيجة \\
\hline \multicolumn{5}{|c|}{20} & نتيجة القيمة القصوى \\
\hline \multicolumn{2}{|c|}{$\% 85$} & \multicolumn{3}{|r|}{$100 \times(20: 17)$} & نسبة المطابقة \\
\hline
\end{tabular}


الاستفادة من دراسة علم الأصيوات في التراث العربي هي تعليم النبر الصحيح ومعرفة كيفية نطقه، ممارسـة الترمين وتسهيل تعليم التنغيم السـديد. ومن أبرز الألة التي تبين مكانة علم الأصهوات في الدرس اللغوي، إسهامه في الحفاظ على اللغة القومية، ودعمها بالأدوات التي تمكنها من التطور والنجاح

بناءً على نتائج البحث في الفصل السابق، تم إدراج ملاءمة عناصر الأصوات في كتاب العربية للناشئين "2" في الفئة غير الملائمة لأنّ قيمة نسبة المطابقة كانت 25\%. عناصر الأصهوات في كتاب العربية للناشئين "2" لا يتوافق مع أحكام عناصر الأصوات ولا يلبي جميع المكونات المستخدمة كمرجع لإعداد الكتب المدرسية.

الجدول 2 : نتيـجة تحليل عناصر اللغة (الأصيوات)

\begin{tabular}{|c|c|c|c|c|c|}
\hline \multicolumn{4}{|c|}{ الدرجة } & \multirow{2}{*}{ المؤشرات } & \multirow{2}{*}{ عناصر اللغة } \\
\hline 4 & 3 & 2 & 1 & & \\
\hline & & & $\mathrm{V}$ & 1. أهداف التعلم & \multirow{5}{*}{ الأصهوات } \\
\hline & & & V & 2. المواد التعليمية & \\
\hline & & & $\mathrm{V}$ & 3. الأمثلة والرسوم التوضيحية & \\
\hline & & & $\mathrm{V}$ & 4. تدريبات وتمرينات & \\
\hline & & & V & 5. الواجبات الذاتي & \\
\hline \multicolumn{5}{|c|}{5} & النتيجة \\
\hline \multicolumn{5}{|c|}{20} & نتيجة القيمة القصهوى \\
\hline \multicolumn{2}{|c|}{$\% 25$} & \multicolumn{3}{|r|}{$100 \times(20: 5)$} & نسبة المطابقة \\
\hline
\end{tabular}

بناءً على نتائج البحث في الفصل السابق، تم إدراج ملاءمة عناصر التراكب في كتاب العربية للناشئين "2" في فئة مناسبة جدا لأن قيمة النسبة المئوية للملاءمة هي 85\%. يشمل من المكونات المستخدمة كمرجع لإعداد الكتب المدرسية بفئات مناسبة للغاية، وهي مكونات تدريبات وتمرينات التعلم والواجبات الذاتياة،

ووفقًا لمكونات المواد التعليمية بالإضيافة إلى الأمثلة والرسوم التوضيحية للتعلم. ومع ذلك، فإن مكونات أهداف التعلم تقع في الفئة غير مناسبة لأنّ كتاب العربية للناشئين "2" لا يقدم أهدافًا تعليمية تتعلق بعنصر لغة التركيب. 


\section{الجدوال 3 : نتيجة تحليل عناصر اللغة (التراكب)}

\begin{tabular}{|c|c|c|c|c|c|}
\hline \multicolumn{4}{|c|}{ 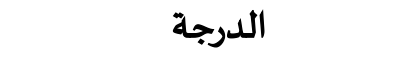 } & \multirow{2}{*}{ المؤشرات } & \multirow{2}{*}{ عناصر اللغة } \\
\hline 4 & 3 & 2 & 1 & & \\
\hline & & & V & 1. أهداف التعلم & \multirow{5}{*}{ 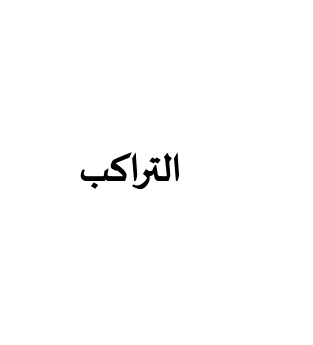 } \\
\hline & $\mathrm{V}$ & & & 2. المواد التعليمية & \\
\hline & V & & & 3. الأمثلة والرسوم التوضيحية & \\
\hline V & & & & 4. تدريبات وتمرينات & \\
\hline V & & & & 5. الواجبات الذاتي & \\
\hline \multicolumn{5}{|c|}{15} & النتيجة \\
\hline \multicolumn{5}{|c|}{20} & نتيجة القيمة القصهوى \\
\hline \multicolumn{2}{|c|}{$\% 75$} & \multicolumn{3}{|r|}{$100 \times(20: 15)$} & نسبة المطابقة \\
\hline
\end{tabular}

ومن أهداف الاستماع عند الناقة التعرف على الأصوات المنطوقة وتنغيم الجملة، معرفة المعنى الإجمالي من التعبيرات المسموعاة، فهم الرسالة والنقاش في تطبيقها (Wahyudin, 2019). بناءً على نتائج البحث في الفصل السابق، تم إدراج ملاءمة عناصر الاستماع في كتاب العربية للناشئين "2" في فئة غير مناسبة لأنّ قيمة النسبة المئوية للملاءمة هي 30 \%. العنصر اللغوي للاستماع في كتاب العربية للناشئين "2" لا يتوافق مع أحكام العناصر اللغوية لأنها يحقق مكونًا إلاّ واحدًا كمرجع لإعداد الكتب المدرسية، وهو الأمثلة والرسوم التوضيحية التعلم مع الفئات الكافية المقابلة. أما بالنسبة للمكونات الأخرى لكتاب العربية للناشئين "2" المتعلق بالعناصر اللغوية لا يفي بالمرة.

الجدوال 4 : نتيجة تحليل عناصر اللغة (الاستماع)

\begin{tabular}{|c|c|c|c|c|c|}
\hline \multicolumn{4}{|c|}{ الدرجة } & \multirow{2}{*}{ المؤشرات } & \multirow{2}{*}{ عناصر اللغة } \\
\hline 4 & 3 & 2 & 1 & & \\
\hline & & & $\mathrm{V}$ & 1. أهداف التعلم & \multirow{5}{*}{ الاستماع } \\
\hline & & & V & 2. المواد التعليمية & \\
\hline & & V & & 3. الأمثلة والرسوم التوضيحية & \\
\hline & & & V & 4. تدريبات وتمرينات & \\
\hline & & & V & 5. الواجبات الذاتي & \\
\hline \multicolumn{5}{|c|}{6} & النتيجة \\
\hline \multicolumn{5}{|c|}{20} & نتيجة القيمة القصهوى \\
\hline \multicolumn{2}{|c|}{$\% 30$} & \multicolumn{3}{|r|}{$100 \times(20: 6)$} & نسبة المطابقة \\
\hline
\end{tabular}


أصبحت القراءة تعني ادراك الرموز المكتوبة والنطق بها، ثم استيعابها وترجمتها إلى أفكار وفهم المادة المقروءة ثم التفاعل مع ما يقرأ، وأخيرّا الاستجابة لما تملياه هذه الرموز. والقراءة عمل فكري من اكتساب المعرفة والتلذذ بطرائف ثمرات العقول (الرحمن, 2017). بناءً على نتائج البحث في الفصل السابق، تم إدراج ملاءمة عناصر القراءة في كتاب العربية للناشئين "2" في فئة غير مناسبة لأنّ قيمة النسبة المئوية للملاءمة هي 35 \%. العنصر اللغوي للقراءة في كتاب العربية للناشئين "2" لا يتوافق مع أحكام العناصر اللغوية لأنها يحقق مكونًا إلاّ واحدًا كمرجع لإعداد الكتب المدرسية، وهو التمرينات والتدريبات مع الفئات الكافية المقابلة. أما بالنسبة للمكونات الأخرى لكتاب العربية للناشئين "2" المتعلق بالعناصر اللغوية 'لا يفي بالمرة.

الجدول 5 : نتيجة تحليل عناصر اللغة (القراءة)

\begin{tabular}{|c|c|c|c|c|c|}
\hline \multicolumn{4}{|c|}{ الدرجة } & \multirow{2}{*}{ المؤشرات } & \multirow{2}{*}{ عناصبر اللغة } \\
\hline 4 & 3 & 2 & 1 & & \\
\hline & & & $\mathrm{V}$ & 1. أهداف التعلم & \multirow{5}{*}{ 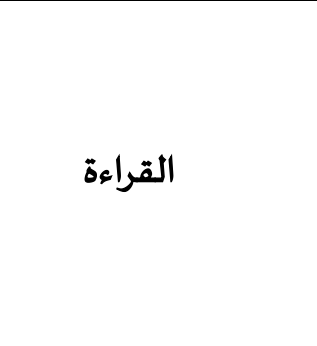 } \\
\hline & & & V & 2. المواد التعليمية & \\
\hline & & & $\mathrm{V}$ & 3. الأمثلة والرسوم التوضيحية & \\
\hline & V & & & 4. تدريبات وتمرينات & \\
\hline & & & V & 5. الواجبات الذاتي & \\
\hline \multicolumn{5}{|c|}{7} & النتيجة \\
\hline \multicolumn{5}{|c|}{20} & نتيجة القيمة القصوى \\
\hline \multicolumn{2}{|c|}{$\% 35$} & \multicolumn{3}{|r|}{$100 \times(20: 7)$} & نسبة المطابقة \\
\hline
\end{tabular}

يرتبط الكلام بتحصيل المعلومات والحقائق والأفكار والخبرات على تكوين الجمل، وبناء العبارة والفقرات، والربط بين ما يقرأه وما يتكلم باه (Ghafir, 2018). وبناءً على نتائج البحث في الفصل السابق، تم إدراج ملاءماة عناصر الكلام في كتاب العربية للناشئين "2" في فئة مناسبة لأنّ قيمة النسبة المئوية للماءمة هي 55 \%

عنصر اللغة الكلام في كتاب العربية للناشئين "2" مناسبا تمامًا مع أحكام عنصر لغة الكلام في الكتاب المدرسي لأنه يلبي ثلاثة المكونات المستخدمة كمرجع لتجميع الكتب المدرسية مع الفئات المناسبة، وهي مكونات المواد التعليمية، الأمثلة والرسوم التوضيحية التعلم. ومع ذلك، يتم تضمين مكونات أهداف التعلم والواجبات الذاتي في فئة غير مناسبة لأنّ كتاب العربية للناشئين "2" لا يقدم أهداف التعلم والواجبات المستقلة المتعلقة بعناصر لغة الكلام. 
الجدول 6 : نتيجة تحليل عناصر اللغة (الكلام)

\begin{tabular}{|c|c|c|c|c|c|}
\hline \multicolumn{4}{|c|}{ 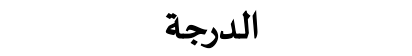 } & \multirow{2}{*}{ المؤشرات } & \multirow{2}{*}{ عناصر اللغة } \\
\hline 4 & 3 & 2 & 1 & & \\
\hline & & & $\mathrm{V}$ & 1. أهداف التعلم & \multirow{5}{*}{ 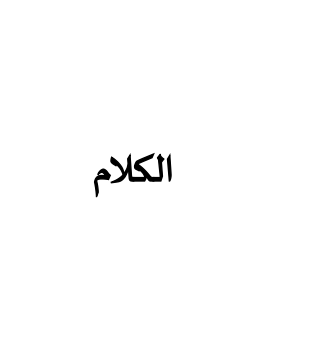 } \\
\hline & & V & & 2. المواد التعليمية & \\
\hline & & V & & 3. الأمثلة والرسوم التوضيحية & \\
\hline & & V & & 4. تدريبات وتمرينات & \\
\hline & & & $\mathrm{V}$ & 5. الواجبات الذاتي & \\
\hline \multicolumn{5}{|c|}{11} & النتيجة \\
\hline \multicolumn{5}{|c|}{20} & نتيجة القيمة القصهوى \\
\hline \multicolumn{2}{|c|}{$\% 55$} & \multicolumn{3}{|r|}{$100 \times(20: 11)$} & نسبة المطابقة \\
\hline
\end{tabular}

تهدف الكتابة لفهم مختلف الخطابات الكتابة وأعرب أيضا عن مجموعة متنوعة من الأغراض. الكتابة هي إتقان اللغة متكاملة أثبتت لإنتاج ما يسمى الكتابة وهي شكل من أشكال الأفكار الصب وفكرة العقل من خلال الرموز المنقوشة اللغة (Nafi'i, 2019).

وبناءً على نتائج البحث في الفصل السـابق، تم إدراج ملاءمة عناصر الكتابة في كتاب العربية للناشئين "2" في فئة مناسبة لأنّ قيمة النسبة المئوية للملاءمة هي 60\%. تتوافق عناصر الكتابة في كتاب العربية للناشئين "2" مع أحكام العناصر اللغوية للكتاب المدرسي لأنها تفي بالعديد من المكونات المستخدمة كمرجع لإعداد الكتب المدرسية، وتدرج عناصر تدريبات وتمرينات التعلم في الفئة المناسباة، ويتضمن الواجبات الذاتي في فئة مناسبة جدًا، بما في ذلك المواد التعليمية بالإضافة إلى أمثلة ورسوم توضيحية للتعلم في الفئة الصحيحة. ومع ذلك، يتم تضمين عنصر أهداف التعلم في فئة غير دقيقة لأنه كتاب العبية للناشئين "2" لا يقدم أهداف التعلم المتعلقة بعناصر كتب اللغة. الجدول 7 : نتيجة تحليل عناصر اللغة (الكتابة)

\begin{tabular}{|c|c|c|c|c|c|}
\hline \multicolumn{4}{|c|}{ الدرجة } & \multirow{2}{*}{ المؤشرات } & \multirow{2}{*}{ عناصر اللغة } \\
\hline 4 & 3 & 2 & 1 & & \\
\hline & & & $\mathrm{V}$ & 1. أهداف التعلم & \multirow{5}{*}{ 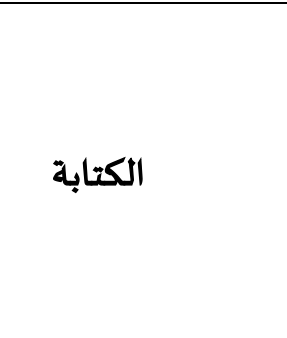 } \\
\hline & & V & & 2. المواد التعليمية & \\
\hline & & V & & 3. الأمثلة والرسوم التوضيحية & \\
\hline & V & & & 4. تدريبات وتمرينات & \\
\hline $\mathrm{V}$ & & & & 5. الواجبات الذاتي & \\
\hline \multicolumn{5}{|c|}{12} & النتيجة \\
\hline
\end{tabular}




\begin{tabular}{|c|c|c|}
\hline \multicolumn{2}{|r|}{20} & تتيجة القيمة القصهوى \\
\hline$\% 60$ & $100 \times(20: 12)$ & نسبة المطابقة \\
\hline
\end{tabular}

\section{مساهمة العناصر اللغوية في كتاب العربية للناشئين "2"}

استخدمت الباحثة البيانات لقياس مساهمة العناصر اللغوية في كتاب العربية للناشئين "2" .

واستخدمت الرموز والمعيار المتعبر لتقويم إنتاج التحليل في هذا البحث، كما يلي :
(النتيجة الحقيقي) (الحة)
الجمدارة
$=P$
$\sum X$
إبحابة $\quad=\Sigma x$
$P=-X 100 \%$
= Exi
$\sum X_{i}$

\begin{tabular}{|c|c|}
\hline النسبة المئوية & الدرجة \\
\hline$\geq 80 \%$ & مناسبا جدا \\
\hline $60 \%-79,9 \%$ & مناسب \\
\hline $50 \%-59,9 \%$ & مناسيا تماما \\
\hline$\leq 49,9 \%$ & أقلّ مناسبا \\
\hline
\end{tabular}

الجدوال 8 : نتيجة الاستبانة لدى الطلاب

\begin{tabular}{|c|c|c|c|c|c|c|c|c|c|c|c|c|c|c|l|c|}
\hline 15 & 14 & $\mathbf{1 3}$ & $\mathbf{1 2}$ & $\mathbf{1 1}$ & $\mathbf{1 0}$ & $\mathbf{9}$ & $\mathbf{8}$ & $\mathbf{7}$ & $\mathbf{6}$ & $\mathbf{5}$ & $\mathbf{4}$ & $\mathbf{3}$ & $\mathbf{2}$ & $\mathbf{1}$ & \multicolumn{1}{|c|}{ مالاس } & $\mathbf{J}$ \\
\hline 3 & 3 & 3 & 3 & 3 & 3 & 3 & 3 & 3 & 4 & 3 & 3 & 4 & 4 & 5 & Hidayatul M. & 1 \\
\hline 3 & 2 & 3 & 4 & 3 & 3 & 4 & 3 & 3 & 4 & 3 & 4 & 3 & 3 & 3 & Naila Binti R. & 2 \\
\hline 4 & 3 & 3 & 3 & 4 & 3 & 3 & 4 & 3 & 4 & 3 & 3 & 3 & 4 & 4 & Afifatul H. & 3 \\
\hline 3 & 3 & 3 & 4 & 3 & 3 & 4 & 4 & 3 & 4 & 3 & 4 & 4 & 4 & 4 & Shabiatur R. & 4 \\
\hline 3 & 3 & 3 & 4 & 3 & 3 & 4 & 3 & 4 & 3 & 3 & 4 & 4 & 4 & 3 & Ardhia P. & 5 \\
\hline 3 & 3 & 4 & 4 & 3 & 4 & 3 & 4 & 3 & 4 & 4 & 3 & 2 & 4 & 4 & Fitri W. & 6 \\
\hline 3 & 3 & 3 & 3 & 5 & 3 & 4 & 2 & 2 & 4 & 4 & 3 & 4 & 4 & 4 & Viranita Q. A & 7 \\
\hline 3 & 3 & 3 & 3 & 3 & 3 & 3 & 3 & 3 & 3 & 3 & 3 & 3 & 3 & 3 & Panji Sholeh & 8 \\
\hline 4 & 4 & 4 & 4 & 4 & 4 & 4 & 5 & 5 & 4 & 4 & 5 & 5 & 5 & 5 & Fitarotunnisa & 9 \\
\hline 5 & 4 & 4 & 3 & 4 & 4 & 3 & 4 & 3 & 5 & 4 & 3 & 4 & 3 & 3 & M. farid & 10 \\
\hline 3 & 2 & 3 & 4 & 2 & 3 & 3 & 2 & 2 & 2 & 4 & 5 & 3 & 1 & 3 & Andika Dwi & 11 \\
\hline 3 & 2 & 2 & 3 & 3 & 2 & 4 & 2 & 2 & 4 & 3 & 2 & 3 & 4 & 3 & Devi Kartika & 12 \\
\hline 3 & 3 & 3 & 3 & 3 & 3 & 3 & 3 & 3 & 3 & 3 & 3 & 3 & 4 & 3 & M. Abid & 13 \\
\hline 4 & 3 & 3 & 4 & 3 & 3 & 4 & 4 & 5 & 5 & 3 & 4 & 3 & 4 & 3 & Fakhriyah & 14 \\
\hline 1 & 5 & 2 & 1 & 1 & 1 & 2 & 3 & 2 & 1 & 1 & 2 & 2 & 3 & 3 & Fitrotul & 15 \\
\hline
\end{tabular}




\begin{tabular}{|c|c|c|c|c|c|c|c|c|c|c|c|c|c|c|c|c|}
\hline 3 & 3 & 3 & 3 & 3 & 3 & 3 & 3 & 3 & 3 & 3 & 3 & 4 & 4 & 3 & Dini Maliya & 16 \\
\hline 3 & 3 & 3 & 3 & 3 & 3 & 3 & 3 & 3 & 3 & 3 & 3 & 3 & 4 & 3 & Mifta & 17 \\
\hline 4 & 3 & 4 & 3 & 2 & 3 & 4 & 4 & 3 & 2 & 3 & 4 & 4 & 4 & 3 & Nur Fadila & 18 \\
\hline 3 & 3 & 3 & 3 & 3 & 3 & 3 & 3 & 3 & 3 & 3 & 3 & 3 & 3 & 3 & Tantini & 19 \\
\hline 3 & 3 & 3 & 3 & 3 & 3 & 3 & 3 & 3 & 3 & 3 & 3 & 3 & 3 & 3 & Endah Sri & 20 \\
\hline 3 & 3 & 3 & 3 & 3 & 3 & 3 & 3 & 3 & 3 & 3 & 3 & 3 & 3 & 3 & Nur Alifah & 21 \\
\hline 3 & 3 & 3 & 4 & 3 & 3 & 4 & 3 & 4 & 4 & 3 & 3 & 3 & 4 & 3 & Badriatut $\mathrm{T}$. & 22 \\
\hline 3 & 4 & 4 & 3 & 2 & 3 & 4 & 3 & 3 & 2 & 3 & 3 & 3 & 4 & 3 & Sunmiyah & 23 \\
\hline 4 & 1 & 3 & 4 & 4 & 4 & 3 & 4 & 4 & 5 & 3 & 4 & 3 & 4 & 4 & Nur Azlina & 24 \\
\hline 3 & 4 & 3 & 3 & 4 & 3 & 4 & 4 & 3 & 3 & 3 & 3 & 4 & 5 & 3 & Laila Fathiya & 25 \\
\hline 3 & 2 & 3 & 4 & 3 & 3 & 4 & 4 & 4 & 4 & 3 & 4 & 3 & 4 & 3 & Ani $\mathrm{H}$. & 26 \\
\hline 2 & 5 & 3 & 3 & 3 & 2 & 2 & 3 & 3 & 2 & 2 & 2 & 3 & 2 & 2 & Siti Hidayati & 27 \\
\hline 4 & 4 & 3 & 3 & 3 & 4 & 3 & 3 & 3 & 2 & 3 & 3 & 2 & 4 & 3 & Siti Najiah & 28 \\
\hline 3 & 3 & 5 & 3 & 4 & 3 & 3 & 5 & 3 & 4 & 4 & 4 & 3 & 4 & 4 & Munadhifah & 29 \\
\hline 2 & 2 & 2 & 3 & 3 & 4 & 4 & 3 & 3 & 4 & 3 & 3 & 3 & 4 & 3 & Mufidatul U. & 30 \\
\hline 4 & 2 & 4 & 4 & 3 & 4 & 4 & 5 & 3 & 4 & 4 & 4 & 3 & 4 & 4 & Dewi M. & 31 \\
\hline 5 & 4 & 5 & 4 & 5 & 5 & 5 & 5 & 5 & 5 & 5 & 5 & 4 & 5 & 4 & Zakiya F. & 32 \\
\hline 5 & 5 & 5 & 5 & 5 & 5 & 5 & 5 & 5 & 5 & 5 & 5 & 5 & 5 & 5 & M. Farih & 33 \\
\hline 5 & 5 & 5 & 4 & 4 & 4 & 4 & 4 & 4 & 4 & 4 & 4 & 4 & 4 & 5 & Nur Karima & 34 \\
\hline 2 & 4 & 5 & 2 & 4 & 3 & 4 & 5 & 3 & 4 & 5 & 3 & 4 & 2 & 3 & Siti Suwaiba & 35 \\
\hline 3 & 4 & 2 & 5 & 4 & 2 & 4 & 5 & 3 & 4 & 3 & 5 & 4 & 5 & 4 & Adi Yusuf & 36 \\
\hline 3 & 1 & 3 & 2 & 3 & 4 & 4 & 4 & 4 & 3 & 4 & 3 & 4 & 4 & 3 & Sonia Prana & 37 \\
\hline 4 & 3 & 3 & 4 & 4 & 3 & 3 & 4 & 3 & 4 & 3 & 4 & 3 & 3 & 4 & M. Hamdani & 38 \\
\hline 3 & 3 & 4 & 4 & 4 & 3 & 3 & 3 & 4 & 2 & 3 & 3 & 4 & 4 & 4 & Fadlan $\mathrm{H}$. & 39 \\
\hline 2 & 1 & 5 & 5 & 4 & 5 & 3 & 5 & 4 & 3 & 4 & 5 & 3 & 5 & 4 & Abyan Safli & 40 \\
\hline 4 & 3 & 3 & 4 & 4 & 3 & 4 & 3 & 4 & 4 & 4 & 4 & 4 & 4 & 4 & Dira R. & 41 \\
\hline 1 & 4 & 1 & 2 & 2 & 2 & 1 & 1 & 3 & 2 & 1 & 1 & 1 & 1 & 1 & Salmawati R. & 42 \\
\hline 5 & 3 & 5 & 5 & 4 & 5 & 5 & 4 & 5 & 5 & 5 & 5 & 4 & 5 & 4 & Amilatul L. & 43 \\
\hline 3 & 3 & 2 & 4 & 3 & 3 & 4 & 2 & 2 & 5 & 2 & 4 & 3 & 3 & 4 & Qorirotu Aini & 44 \\
\hline 3 & 2 & 2 & 3 & 3 & 3 & 4 & 2 & 4 & 5 & 5 & 4 & 3 & 4 & 4 & Ana Fauziah & 45 \\
\hline 3 & 3 & 4 & 3 & 4 & 5 & 5 & 3 & 4 & 3 & 3 & 3 & 4 & 5 & 4 & Hikmatul L. & 46 \\
\hline 5 & 4 & 5 & 2 & 2 & 2 & 1 & 1 & 2 & 2 & 1 & 1 & 1 & 1 & 1 & Samawati R. & 47 \\
\hline
\end{tabular}


الجدول 9 : نتيجة تحليل الاستبانة لدى الطلاب

\begin{tabular}{|c|c|c|c|c|c|c|c|c|c|c|}
\hline الرقم & البيان & 5 & 4 & 3 & 2 & 1 & $\sum X$ & $\sum X I$ & $P$ & التقرير \\
\hline 1 & كتاب العربية للناشئين هو العبية باستخدام & 25 & 64 & 69 & 2 & 2 & 162 & 240 & $\% 67.5$ & مناسيا تماما \\
\hline 2 & 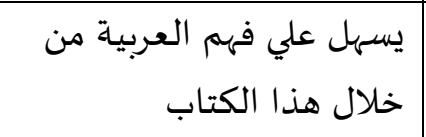 & -4 & 96 & 30 & 4 & 3 & 173 & 240 & $\% 72.1$ & مناسيا تماما \\
\hline 3 & كتاب العربية للناشئين & 10 & 68 & 69 & 6 & 2 & 155 & 240 & \%64.6 & أقل مناسبا \\
\hline 4 & 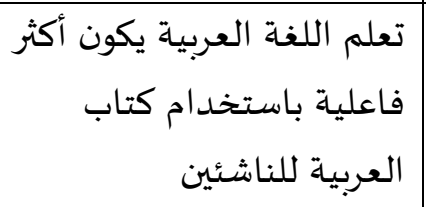 & 35 & 56 & 63 & 6 & 2 & 162 & 240 & $\% 67.5$ & مناسيا تماما \\
\hline 5 & للغاية اللغة بهذا الكتاب ممتع & 25 & 44 & 78 & 4 & 3 & 154 & 240 & $\% 64.2$ & أقل مناسبا \\
\hline 6 & إتقان مادة المفردات لقداعدني هذا الكتاب في & 40 & 72 & 36 & 16 & 1 & 165 & 240 & $\% 68.8$ & مناسيا تماما \\
\hline 7 & كهاب العربية للناشئين التحدث والكتابة مع أسئ في & 25 & 44 & 75 & 12 & 0 & 156 & 240 & $\% 65$ & مناسيا تماما \\
\hline 8 & للناشئين أكثر كفاءة من الطتاب العبية & 40 & 48 & 60 & 10 & 2 & 160 & 240 & \%66.7 & مناسيا تماما \\
\hline 9 & كتاب العبية للناشئين & 20 & 84 & 54 & 4 & 2 & 164 & 240 & $\% 68.3$ & مناسيا تماما \\
\hline 10 & 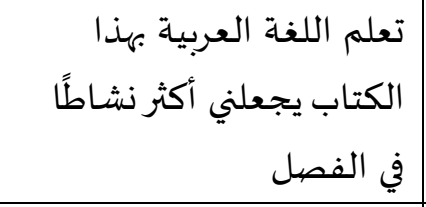 & 25 & 32 & 81 & 12 & 1 & 151 & 240 & $\% 62.9$ & أقل مناسبا \\
\hline 11 & 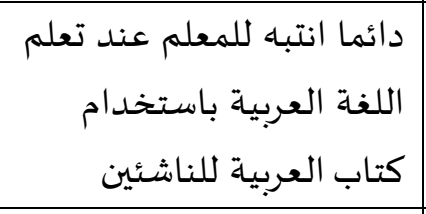 & 15 & 60 & 69 & 10 & 1 & 155 & 240 & $\% 64.6$ & أقل مناسبا \\
\hline 12 & للناشئين في حفاعدني كتاب العربية الدروس & 20 & 68 & 60 & 8 & 1 & 157 & 240 & \%65.4 & مناسيا تماما \\
\hline 13 & | أحب كتاب العربية للناشئين & 35 & 32 & 72 & 12 & 2 & 153 & 240 & $\% 63.8$ & أقل مناسبا \\
\hline
\end{tabular}




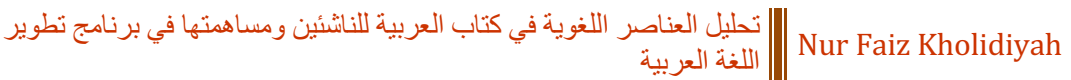

\begin{tabular}{|c|c|c|c|c|c|c|c|c|c|c|}
\hline & مقارنة بالكتب الأخرى & & & & & & & & & \\
\hline 14 & الجدب صبعوبة في تعلم اللغة & 20 & 36 & 69 & 16 & 3 & 144 & 240 & $\% 60$ & أقل مناسبا \\
\hline 15 & إن العربية للناشئين يؤثر استخدام كتاب & 25 & 36 & 78 & 8 & 3 & 150 & 240 & $\% 62.5$ & أقل مناسبا \\
\hline \multicolumn{7}{|c|}{ النتيجة } & 2361 & 3600 & $\% 65.6$ & مناسبا تماما \\
\hline
\end{tabular}

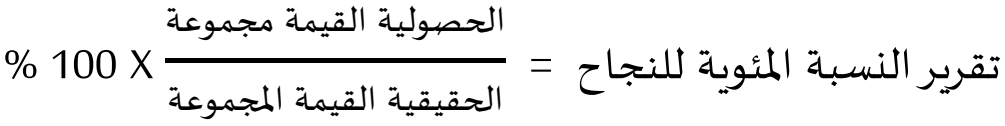

$$
\begin{aligned}
& \% 100 \times \frac{2361}{3600}= \\
& \% 65.6=
\end{aligned}
$$

من البيان السـابق، واضح لنا أنّ مساهمة في برنامج تطوير اللغة العربية جامعة الإسلامية الحكومية مولانا مالك إبراهيم مالانج بالنسبة 6،65 \%، فهذه النتيجة تضهم إلى مناسبا تماما.

\section{خاتمة}

عناصر المطابقة الواردة في كتاب العبية للناشئين "2" مع عناصر لغوية عنصر واحد مدرجة في الفئة المناسبة للغاية وهي عنصر المفردات بنسبة 85\% ، وهما عنصران لغويان ضمن الفئة المناسبة، وهما عنصر الكتابة والتركيب بنسبة مئوية. 60\% و 75\% على التوالي، ثم عنصر واحد يدخل في الفئة المناسبة تمامًا وهو عنصر الكلام بنسبة 55\% ، و ثلاثة عناصر لغوية تدخل في التصنيف غير المناسب، وهي عناصر الأصيوات والاستماع والقراءة بالنسب المئوية 25\% و 30\% و 35\% على التوالي. بحيث يتم استخدام كتاب العربية للناشئين "2" بشكل جيد في عملية تعلم عناصر لغة المفردات والتركيب والكتابة بسبب نسبتها العالية. أما بالنسبة لتعلم عناصر الكلام ، فإن كتاب العربية للناشئين "2" جيد جدًا لأن النسبة كافية. أما بالنسبة لتعلم عناصر لغة الأصيوات والاستماع والقراءة، فلا يوصى بكتاب العربية للناشئين "2"، لأن نسبة المطابقة منخفضية للغاية. 
Abrar, M. (2017). تحليل المواد في كتاب “Aku Cinta Bahasa Arab MI Kelas V." Al Ta'rib, 5(2), 126151.

Amiruddin, Muhammad; Akhyar, M. A. (2019). Tahlil Kitab Muqarrar al Lughah al 'Arabiyyah li al Jami'ah al Juz at Tsaniy Thiba' at 2012 'ala Asas Muwashafaat 'Idad al Kutub al Muqarrarah. Lughawiyyāt: Jurnal Pendidikan Bahasa Dan Sastra Arab, 2(1), 66-103. Retrieved from http://ejournal.iaidalwa.ac.id/index.php/Lughawiyyat/article/view/149

Ghafir, A. (2018). الخطوات المناسبة عند الطريقة المباشرة والسمعية الثفهية لتدريس مهارة الكلام. Al Mahara, 4(1), $1-24$.

Hafidz, M. (2018). تطوير المواد التعليمية لترقية مهارة الكتابة. Nidhomul Haq, 3(1), 1-17.

Halim, N. (2020). Analisis Teks Qiro'ah dalam Kitab Al Arobiyah Lin Naasiin Jilid 2 dalam Efektifitas Pembelajaran. Palapa, 8(1), 113-128. https:// doi.org/10.36088/palapa.v8i1.701

Halimah, A. (2019). تعليم مهارة القر اءة للناطقين بغير ها. Lisanuna, 9(2), 249-259.

https://doi.org/http:/ / dx.doi.org/10.22373/ls.v9i2.6744

Hamid, M. abdul, Baharuddin, U., \& Mustofa, B. (2008). Pembelajaran Bahasa Arab ( Pendekatan, Metode, Strategi, Materi dan Media (Muallif, ed.). Malang: UIN - Malang Press.

Hasan, N. (2018). علم الأصوات العربية؛ تطور اتها ونظريتها والإستفادة منها لتعليم اللغة العربية. Al - Ta'rib, 6(2), 143-156. https://doi.org/https:/ /doi.org/10.23971/altarib.v6i2.1070

Hasanah, I. H. تعليم المفردات بالبطاقة الرباعية لتلاميذ المدرسة الثانويّة الإسلامية. لساننا, 3(1), 93-105. (2020). https://doi.org/https:/ / ejournal.uinib.ac.id/jurnal/index.php/lisaanuna/article/view/ 1811

Ismail, M. (2019). أساليب بناء منهج التعلم المدمج على أساس التدخل الاتصالي لتنمية مهار ات اللغة العربية للناطقين هisanudhad, 6(2), 147-171.

https://doi.org/http:// dx.doi.org/10.21111/lisanudhad.v6i2.3551

Khoirurrijal, \& Erlina. (2019). مهارة الكلام العربي ومكوّنتها و أهدافها وتقويمها. IJALT, 1(1), 31-41.

Mukmin, M. (2018). I'dâd Durûs Al-Lughah Al-'Arabiyyah 'Ala Dhaui Nazhariyyah Ta'lîm AlLughah Al-'Arabiyyah. Taqdir, 1(1), 45-62. Retrieved from http://jurnal.radenfatah.ac.id/index.php/Taqdir/article/view/648

Nafi'i, W. (2019). تعليم الكتابة : أهدافه و عناصره وتقنياته. El - Wasathiya, 7(112-126).

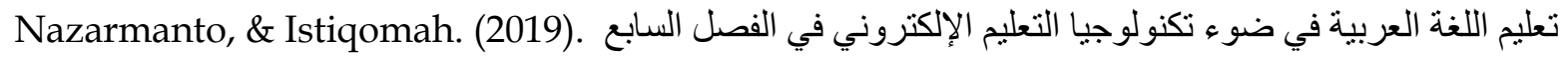
بالمدرسة الثانوية الدينية العلمية الإسلامية الأزهر قاهرة بالمبانج. TAQDIR, 5(1), 1-16.

Prima, A. P., \& Habib, M. T. (2019). تقويم الكتب المدرسية " تعليم اللغة العربية " تأليف د. هدايات في المستوى الثانوي عند ماكدونو وشاوو. Lughowiyyat, 2(2), 113-125.

https://doi.org/https:/ / doi.org/10.38073/lughawiyyat.v2i2.154 
Siddiq, A. A. (2019). تقويم الكتاب التعليمي"العربية للناشئين" لتعليم اللغة العربية لغير الناطقين بها. Waraqat : Jurnal Ilmu - Ilmu Keislaman, 4(2), 106-122. Retrieved from http://www.journal.assunnah.ac.id/index.php/WRQ/article/view/91

Umar, \& Bahruddin. (2018). تطبيق اللعب اللغوي بطاقة الصدر في تعليم اللغة العربية لترقية مهارة الكتابة. Arabia, 10(1), 119-132. https:/ / doi.org/http://dx.doi.org/10.21043/arabia.v10i1.3594

Wahyudin. (2019). تدريس مهارة الاستماع نموذجا لغير الناطقين بها. IJATL : International Journal Of Arabic Teaching and Learning, 03(02), 60-76.

https://doi.org/https:// doi.org/10.33650/ijatl.v3i2.1068

Zulhannan, Z. (2015). عناصر اللغة العربية: أهدافهاو خطو ات تدريسها. Jurnal Al-Bayan: Jurnal Jurusan Pendidikan Bahasa Arab, 7(1), 1-10.

https://doi.org/https:// doi.org/10.24042/albayan.v7i1.5830

الرحمن, ج. (2017). مشاكل القر اءة لدى التلاميذ وحلولها. المجلة العربية الدولية للتربية والتعليج, 01(02), 15-43. السلام, ع. ا. أ. ع. (2020). تعليم المفردات اللغوية العربية للناطقين بغير ها النظرية والنطبيق. مجلة الآداب واللغات والعلوم

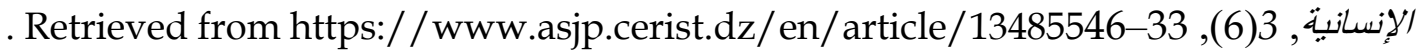

العلم, ه. ح. (2018). تحليل المحتوى الثقافي للكتاب الددرسي "العربية للناشئين KONASBARA, 653-673. Retrieved. from http:// prosiding.arab-um.com/index.php/konasbara/article/view/327 العليمات, ع. م., \& داود, أ. ع. (2019). تطوير وحدات من المناهج الوطني التفاعلي لتحسين مهارة القر اعة والكتابة لدى طفل الروضة في الأردان في ضوء المعايير العالمية. مجلة العلوم التربوية : مجلة علمية فصيلة محكمة, 21 (2), 19-87. الفوزان, م. ب. إ. (2019). تقويم كتاب تعليم اللغة العربية للناطقين بغير ها “العربية للعالم” في ضوء معايير الكتاب التعليمي

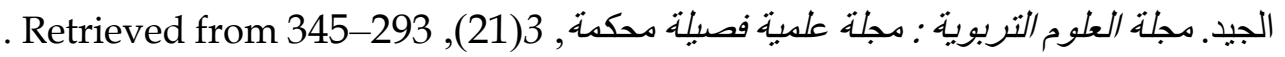
https://www.imamjournals.org/index.php/joes/article/view/345

قدري, م., \& فضل, م. (2019). مواصفات الكتاب المدرسي العربي الجيد : للمرحلة الإبندائية Al - Tarqiyah: Jurnal . . . . Pendidikan Bahasa Arab, 2(1), 21-38.

https://doi.org/http://altarqiyah.ftk.uinjambi.ac.id/index.php/altarqiyah/article/view

لوبيس, س. أ. (2019). مهارة الاستماع وضو ابطها في اللغة العربية Thariqah Ilmiyah: Jurnal Ilmu - Ilmu. Kependidikan Dan Bahasa Arab, 53(9), 1689-1699. https://doi.org/10.1017/CBO9781107415324.004

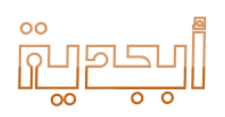

